\title{
EFFECT OF SURFACING ON STRESS-STRAIN STATE OF ROLLERS OF MACHINES FOR CONTINUOUS CASTING OF BILLETS
}

\author{
A.P. GOPKALO and V.V. KLIPACHEVSKY \\ G.S. Pisarenko Institute for Problems of Strength, NASU \\ 2 Timiryazevskaya Str., 01014, Kiev, Ukraine. E-mail: postmaster@ipp.adam.kiev.ua
}

\begin{abstract}
The effect of ratio of physical and mechanical properties of the base and deposited metal on stress-strain state of rollers of machines for continuous casting of billets was considered using numerical modeling. It is shown that by varying the ratio of the coefficient of linear expansion and coefficient of thermal conductivity of base and deposited metals and their mechanical properties it is possible to control the value and sign of thermal stresses on the surface of rollers. 2 Ref., 2 Figures.
\end{abstract}

Key words: roller, surfacing, temperature, stresses, deformation

In engineering practice to increase the life of rollers of machines for continuous casting of billets (MCCB) a metal with higher characteristics of resistance to thermomechanical loading is deposited on their surface [1]. In this work, numerical simulation of estimation of influence of differences in physical and mechanical properties of the base and deposited metals on formation of stress-strain state (SSS) of MCCB rollers was carried out.

Figure 1 shows comparison of calculations of thermal stresses in monolithic (without deposit) MCCB roller of steel $25 \mathrm{Kh} 1 \mathrm{M} 1 \mathrm{~F}$ in elastic (curve 1) and elastic-plastic variants at the temperature dependence of physical characteristics and mechanical properties (curve 2), and also at their fixed $\left(T=20^{\circ} \mathrm{C}\right)$ values (curve 3$)$. As it follows

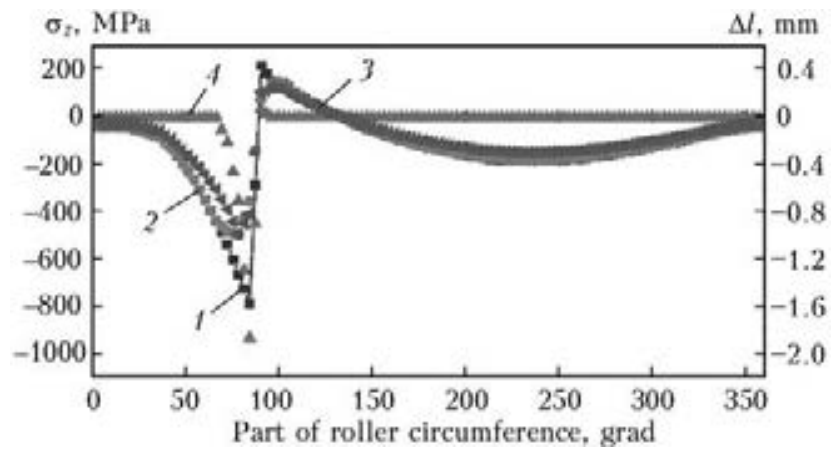

Figure 1. Distribution of calculation thermal stresses $\sigma_{z}$ along the surface of MCCB roller of steel $25 \mathrm{Kh} 1 \mathrm{M} 1 \mathrm{~F}$ contacting with slab in elastic (1) and elastic-plastic variants at the temperature dependence of physical characteristics [2] and mechanical properties (2), and at their fixed $(T=$ $=20^{\circ} \mathrm{C}$ ) values $(3)$, and distribution of plastic deformations $\Delta l$ around the roller circumference (4) from these data, consideration of temperature dependence of thermophysical and mechanical characteristics affects the character of diagram of thermal stresses relatively to the diagram obtained at their fixed values (compare curves 2 and 3). Estimation of SSS of the roller in elastic-plastic variant showed that in the area before contact of roller with slab the plastic compression deformations occur (curve 4), and in the contact zone of roller with slab the tensile deformations occur.

Figure 2 shows diagrams of thermal stresses on the surface of roller circumference part near the contact zone with slab, which were obtained

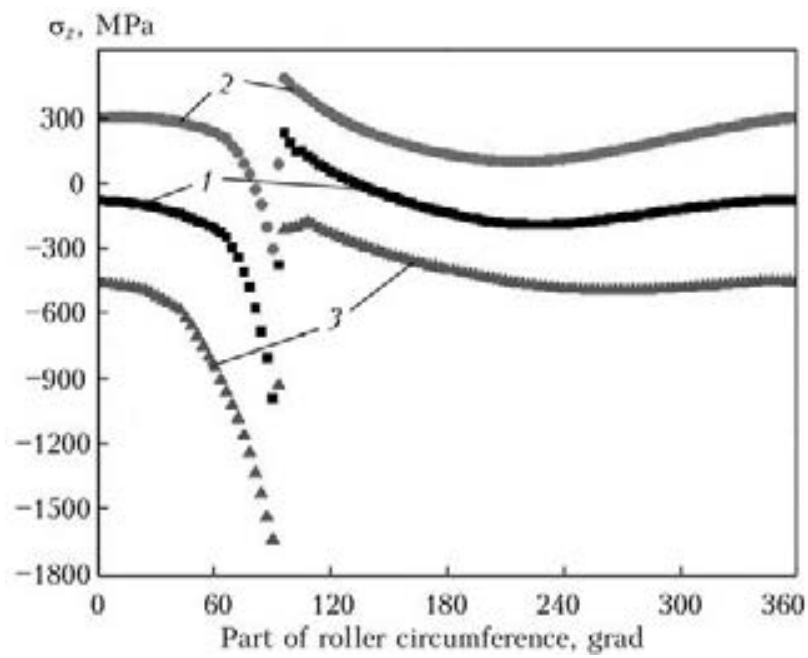

Figure 2. Effect of ratios of CLE of base and deposited metals on distribution of thermal stresses along the surface of MCCB roller (outer diameter of roller $D=300 \mathrm{~mm}$, thickness of deposit layer $\left.t_{1}=15 \mathrm{~mm}\right): 1-\alpha_{1}=\alpha_{2}=$ $=1.35 \cdot 10^{-1} ; c_{1}=c_{2}=45$ (without deposit) $; 2-\alpha_{1}=$ $=1.8 \cdot 10^{-5} ; \alpha_{2}=0.9 \cdot 10^{-5} ; c_{1}=65 ; c_{2}=25 ; 3-\alpha_{1}=0.9 \cdot 10^{-5}$; $\alpha_{2}=1.8 \cdot 10^{-5} ; c_{1}=65 ; c_{2}=25$ (where $c_{1}-$ CTC of base; $c_{2}-$ of deposit; $\alpha_{1}-$ CLE of base; $\alpha_{2}-$ of deposit) 
by calculation in the elastic variant at varying of physical and mechanical characteristics of base and deposited metal. It is considered that at equality of physical and mechanical characteristics of deposited and base metals the roller is monolithic. In this example, the influence of ratios of coefficient of linear expansion (CLE) of base metal and that of deposit on SSS of the roller at the same values of coefficient of thermal conductivity (CTC) is considered. The increase of CLE values of deposited metal by 2 times respectively to base metal causes increase in values of thermal compression stresses in the most loaded zone before the contact of roller with slab (curve 3) by 1.65 times as compared to the corresponding stresses for monolithic roller (curve 1 ). Moreover, on the surface of contact area of roller with slab the thermal compression stresses also occur unlike the monolithic roller, which is characterized by the thermal tensile stresses. The use of metal for surfacing with CLE values by 2 times lower than that for the base metal resulting in 3 times reduction in thermal compression stresses in the contact of roller with slab (2) relatively to the corresponding thermal stresses in the monolithic roller (curve 1). At the same time on surface of the contact area of roller with slab the thermal tensile stresses occur, which are 2.2 times higher than those in the monolithic roller.

Thus, by varying of CLE and CTC ratios of base and deposited metals and their mechanical properties it becomes possible to control the value and sign of thermal stresses on the roller surface. The calculation optimization of these ratios, taking into account the operational mechanical loads can serve as a basis for development of technical solutions not only for recovery of service properties of surface layers of MCCB rollers, but also to increase their life.

1. Bulanov, L.V., Korzunin, L.G., Parfenov, E.P. et al. (2004) Machines for continuous casting of billets. In: Theory and calculation. Kazan: Ural center Marat.

2. (1967) Physical properties of steels and alloys applied in power engineering: Refer. Book. Ed. by B.E. Nejmark. Moscow-Leningrad: Energiya.

Received 29.04.2015 